\title{
Predicted nine-year risk of diabetes among professional divers: a prospective study
}

\section{Richard Pougnet ${ }^{1,2,3}$, Marie Uguen, 3, Grégoire Verdier 2, 3, Laurence Pougnet 3, 4, 5 , David Lucas $^{1}$, Brice Loddé ${ }^{1,2,3}$, Jean-Dominique Dewitte ${ }^{1,2,3}$}

\author{
${ }^{1}$ Maritime Medicine French Society (SFMM), Brest, France \\ ${ }^{2}$ Occupational Disease Centre, University Hospital of Brest, France \\ ${ }^{3}$ European University of Brittany, Brest, France \\ ${ }^{4}$ Medicine School of Val de Grâce, Paris, France \\ ${ }^{5}$ University Military Hospital of Brest, France
}

\begin{abstract}
Background: The purpose of this study was to assess diabetes predictive score for professional divers followed-up in one medical centre in France.

Materials and Methods: This prospective study, performed during 2013, included professional divers who were followed in a French maritime medicine centre. Data about their professional history of diving and dive profiles were collected. The clinical and biological data collected included: age, waist circumference, biometrics, body mass index, smoking status, blood pressure, practicing sports, glycaemia, triglyceridaemia, total cholesterolaemia, HDL and LDL cholesterolaemia. The predicted 9-year risk of diabetes was calculated according to the DESIRE score. Data were analysed using Epidata ${ }^{\circledR}$ software, by Pearson $\chi^{2}$ test or by Fisher's exact test, by analysis of variance or Kruskal-Wallis test, and by Spearman correlation coefficient. Results: Out of the 64 deep-sea divers taking part in the study, diabetes risk was estimated for 60 divers. The predictive 9-year risk of diabetes was higher than $10 \%$ for $31.7 \%$ of the divers and higher than $30 \%$ for $6.7 \%$ of the divers.

Conclusions: In France, people with diabetes have been declared definitely medically unfit to dive. The interest to assess the prevalence of risk factors and the predictive risk of diabetes arises from the need for prevention.
\end{abstract}

(Int Marit Health 2015; 66, 2: 87-92)

Key words: diving, medical history taking, statistics, numerical data, risk assessment methods, diabetes mellitus

\section{INTRODUCTION}

Professional deep-sea diving exposes the body to various forms of stress. Not only do deep-sea divers often have difficult tasks to perform, but their body also has to deal with considerable stress caused by this pressurised environment. We can observe this stress, in particular, on the cardiovascular system [1-3]: accelerating heart beat due to hypercapnia, impact of pressure variations in the airways on chest venous return, changing myocardial contractile function observed in animal experiments etc.
A heart rate monitor study showed the heavy workload of professional deep-sea divers across a range of different tasks [4].

Pougnet et al. [5] studied the prevalence of cardiovascular risk factors in a population of 200 deep-sea divers and calculated the cardiovascular risks. In their study, 66\% of the divers had at least one modifiable risk factor which was obesity in $40 \%$ of this group. They also found that $0.5 \%$ of studied population had diabetes. This low incidence can be explained by the fact that, in France, diabetes is 
Table 1. Score calculation methods for clinical and clinical-biological diabetes risk over a 9 year period according to the Désir study

\begin{tabular}{|c|c|c|c|}
\hline Variables & & Men & Women \\
\hline Clinical score & & & \\
\hline Waist measurement & $70-79 \mathrm{~cm}$ & 0 & 1 \\
\hline & $80-89 \mathrm{~cm}$ & 1 & 2 \\
\hline & $90-99 \mathrm{~cm}$ & 2 & 3 \\
\hline & $>99 \mathrm{~cm}$ & 3 & 3 \\
\hline Smoker & & 1 & 0 \\
\hline Family history of diabetes & & 0 & 1 \\
\hline Blood pressure $\geq 140 \mathrm{~mm} \mathrm{Hg}$ & or $90 \mathrm{~mm} \mathrm{Hg}$ & 1 & 1 \\
\hline Clinical-biological score & & & \\
\hline Waist measurement & $70-79 \mathrm{~cm}$ & 0 & 1 \\
\hline & $80-89 \mathrm{~cm}$ & 1 & 2 \\
\hline & $90-99 \mathrm{~cm}$ & 2 & 3 \\
\hline & $>99 \mathrm{~cm}$ & 3 & 3 \\
\hline Smoker & & 1 & 0 \\
\hline Family history of diabetes & & 0 & 1 \\
\hline Glycaemia & $5.6-5.9 \mathrm{mmol} / \mathrm{L}$ & 2 & 2 \\
\hline & $\geq 6 \mathrm{mmol} / \mathrm{L}$ & 5 & 4 \\
\hline Gamma glutamyl transferase & 20-44 UI/L & 2 & 0 \\
\hline & $\geq 45 \mathrm{UI} / \mathrm{L}$ & 3 & 0 \\
\hline Triglyceridaemia & $\geq 1.1 \mathrm{mmol} / \mathrm{L}$ & 0 & 1 \\
\hline
\end{tabular}

a contraindication to becoming a professional deep-sea diver [6]. In fact, any affliction leading to possible loss of consciousness is incompatible with this professional activity in France [7].

Although deep-sea diving is not a diabetes risk factor, when professional deep-sea divers find out that they have diabetes, this can compromise pursuing their career. In consequence, maritime doctors have to prevent the risk for divers to develop diabetes. Divers can act on modifiable risk factor (overweight, smoking...). The object of this study is therefore to evaluate, in a population of professional deep-sea divers, the predicted 9-year risk of diabetes and to discuss ways of preventing it.

\section{MATERIALS AND METHODS}

This was a prospective study done on professional deepsea divers in a Consultation Centre for Environmental, Occupational and Maritime IIInesses in a University Research Hospital in France, from $1^{\text {st }}$ February 2013 to $31^{\text {st }}$ October 2013. The parameters were registered during the last consultation carried out by a doctor. Socio-professional details (age, gender, work, years of service, family and medical history) were recorded; as well as the characteristics of deep-sea diving performed (how many professional and personal diving expeditions per year, how deep and for how long - average and maximum length of time); lifestyle (smoking, sport); body mass index (BMI); waist circumference measurement; electrocardiogram (ECG) at rest; a cardiac stress test and biological test results (glycaemia, total cholesterolaemia and triglyceridaemia, gamma glutamyl transferase [GGT]). Some divers also provided their HDL and LDL cholesterolaemia.

The risk of diabetes was calculated using the Désir study model [8]. This is an adaptation of the Findrisc score for the French population [9, 10]. These studies showed that this scoring system was better adapted to the French population. The Désir study developed two scoring systems for diabetes risk over a 9 year period: a clinical score and a clinical-biological score. Each score was calculated differently for men and women. The clinical score may range from 0 to 5; and the clinical-biological score may range from 0 to 13 for men and from 0 to 9 for women (Table 1). The scores were then calculated depending on gender and biological and clinical parameters.

The results were recorded and analysed using Epidata ${ }^{\circledR}$ software. The mean and median values of the parameters were calculated. Comparison of qualitative variables was done using Pearson's $\chi^{2}$ test and Fisher's exact test 


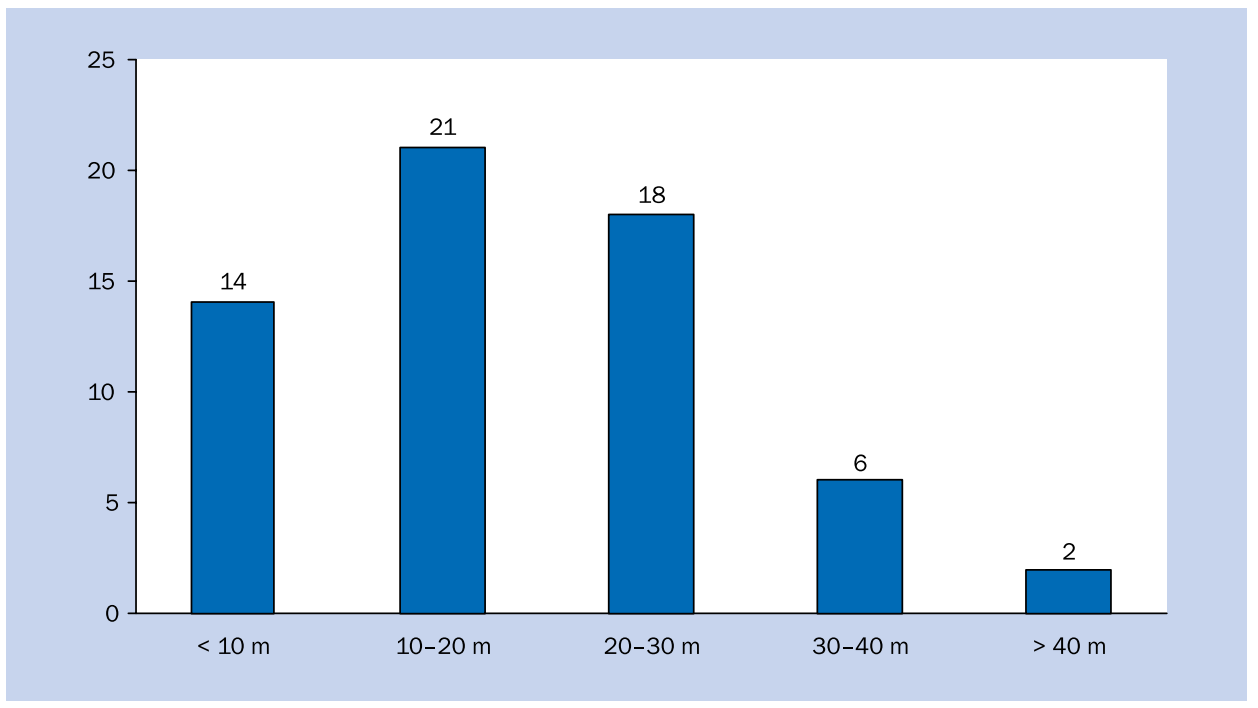

Figure 1. Number of divers according to usual diving depth

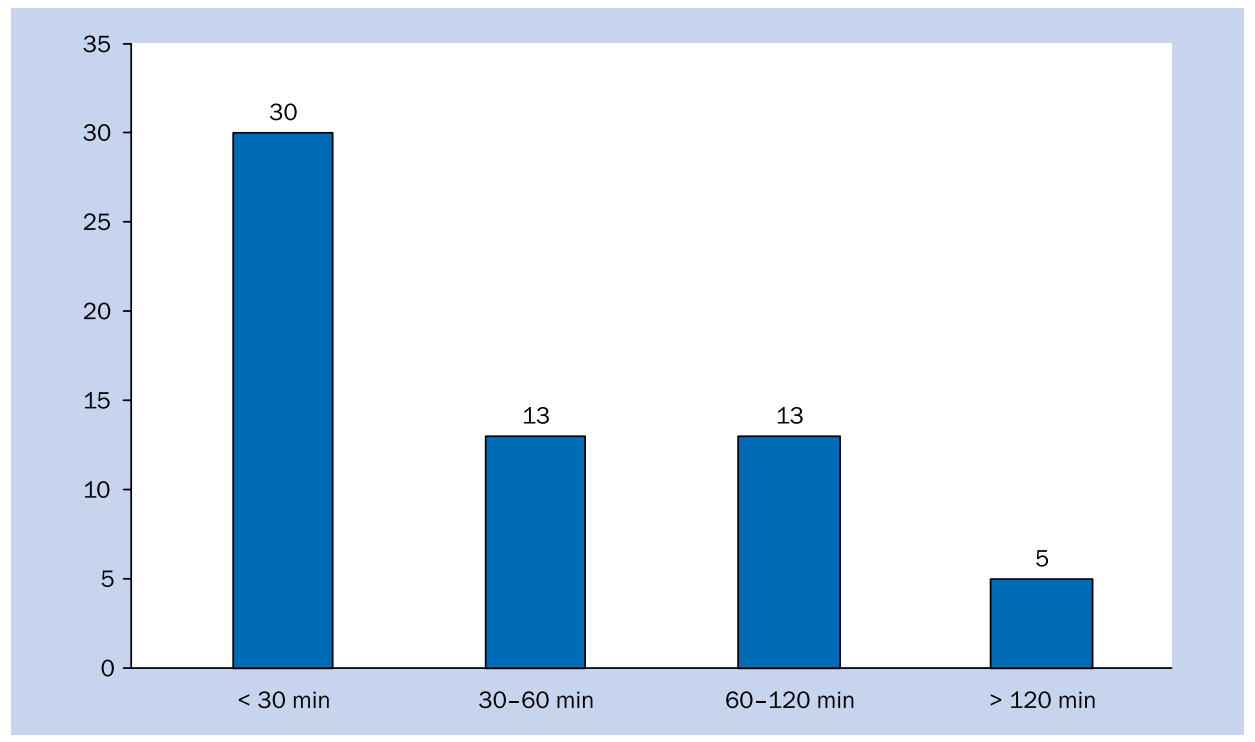

Figure 2. Numbers of dives according to usual diving duration

(depending on the validity conditions of parametric testing). Quantitative variables were compared using the Kruskall-Wallis variance analysis test (depending on the validity conditions of parametric testing). Correlations were examined using Spearman's correlation coefficient. Divers were divided into two groups according to their BMI (normal if $\mathrm{BMI}<25$, abnormal if $>25$ ).

\section{RESULTS}

\section{DESCRIPTION OF THE POPULATION}

Sixty four divers took part in the study; 55 (86\%) were men and 9 (14\%) women (Table 1). The average age for women was 33 years and for men 41 years $(p=0.27$ ). The type of deep-sea diving performed by divers varied considerably (Figs. 1, 2): 5 divers went diving for over 2 h; 1 of them dived for up to consecutive $4 \mathrm{~h}$ and another diver went down to a depth of $80 \mathrm{~m}$.

\section{ANALYSIS OF THE CLINICAL AND BIOLOGICAL PARAMETERS}

Analysis of the clinical score parameters showed that 19 (30.6\%) divers were smokers and 12 (19.4\%) had high blood pressure (Table 2). Glycaemia in men were higher than that in women: $5.2 \pm 0.5$ vs. $4.8 \pm 0.5 \mathrm{mmol} / \mathrm{L}$. Amongst male divers, 15 (28.8\%) had glycaemia over $5.6 \mathrm{mmol} / \mathrm{L}$. 
Table 2. Description of the population: divers profiles

\begin{tabular}{ll}
\hline Item & Male $55(87 \%)$ vs. female $9(14 \%)$ \\
\hline Gender & $40.3 \pm 8.8$ years \\
Age & $6(9.5 \%)$ \\
Treatment* & $45(71.4 \%)$ class 1 and \\
Class & $18(28.6 \%)$ class 2 \\
& $44.1 \pm 62.4$; maximum 365 \\
Number of dives per year & $16.1 \pm 10.3$ m; maximum 80 m \\
Usual depth of dives & $48.9 \pm 38.1$ min; maximum 240 min \\
Usual duration of dives & *1 case treated with anti-histamines, 2 with proton pump inhibitors and 3 with \\
oral contraception.
\end{tabular}

\section{CLINICAL AND CLINICAL-BIOLOGICAL SCORES OF DIABETES RISK}

Scores were calculated for 60 divers. Forty $(66.7 \%)$ divers had the predicted 9-year risk of diabetes below $5 \%$ (Fig. 3). The predicted 9-year risk of diabetes in 19 (31.7\%) divers was higher than $10 \%$ (Fig. 3). High clinical score was more frequently observed in men: 18 vs. $2(p=0.36)$ (Table 3).

Table 4 shows predicted 9-year risk of diabetes among male and female divers according to clinical-biological score.

\section{DISCUSSION}

Despite medical examination, some divers had a high diabetes risk, so that maritime doctors should act to minimize this risk. Out of 64 deep-sea divers taking part in the study, calculation of diabetes risk was done for 60 divers. The predicted 9-year risk of diabetes was higher than 10\% for $31.7 \%$ of the divers and higher than $30 \%$ for $6.7 \%$ of the divers. Modifiable diabetes risk factors were shown. For example, in this population, $28.8 \%$ had glycaemia over $5.6 \mathrm{mmol} / \mathrm{L}$. Maritime doctors could implement appropriate treatment.

Our study was, however, limited. The population studied was made up of 60 deep-sea divers from the same geographical area; therefore not representative of the whole French professional diving population. Findrisc scoring was not chosen, making comparisons difficult with international literature. However, the model chosen was used on a French population, aged from 30 to 64 years. Given that the centre in Brest monitor professional French divers with an average age of 40 , it seemed more adapted to our population.

The interesting point of this study was to show the risk of developing a pathology which has both medical and professional consequences. There are numerous medical consequences: blindness caused by diabetic retinopathy [11]; $21 \%$ to $40 \%$ of diabetic neuropathy cases [12, 13]; up to $29 \%$ of occlusive arteriopathy cases of the lower limbs [14], not forgetting $50-70 \%$ of cases of skin conditions [15] and so on. Regarding professional consequences, diabetes can put a stop to a career in deep-sea diving. In other words, in this study we can estimate that $6.7 \%$ of divers have over $30 \%$ risk of having to change their careers in a 9-year time span.

Prevention issues are therefore doubly important for this population: due to health as well as professional reasons. This idea of prevention is also applicable to a wider field of epidemiological increase of type 2 diabetes within populations of Western countries from now until $2030[16,17]$.

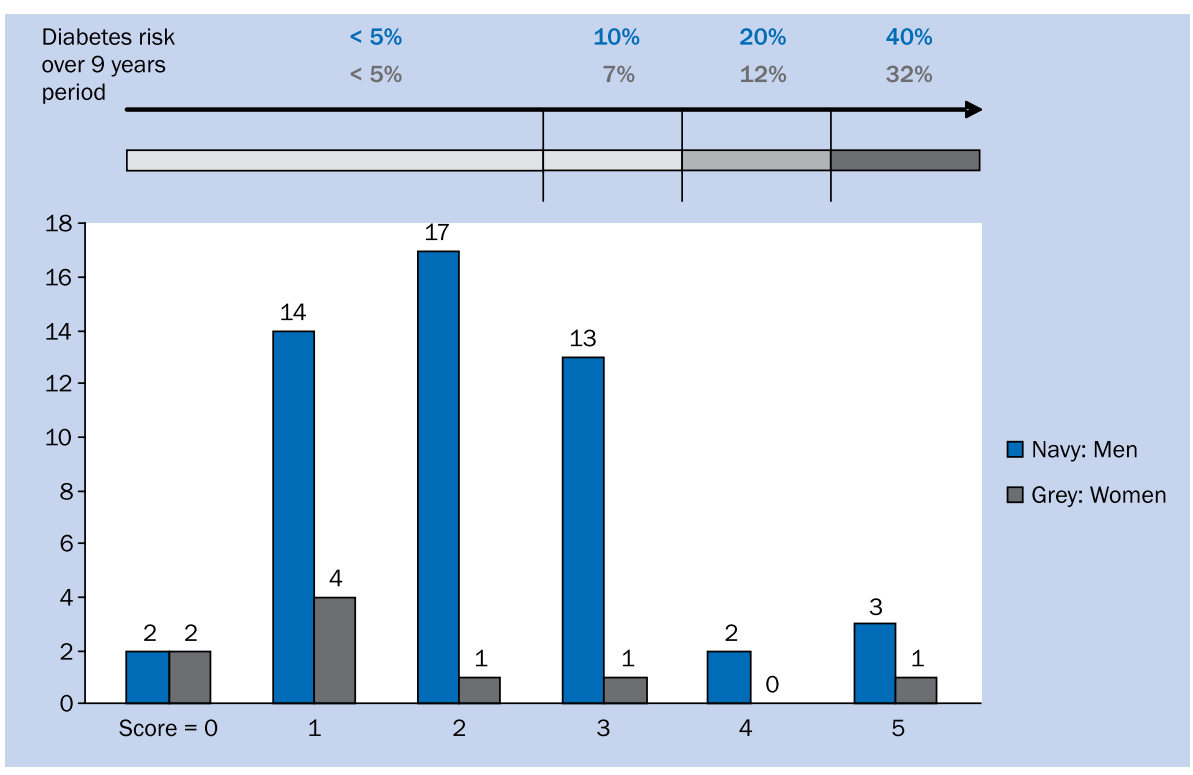

Figure 3. Clinical score numbers and diabetes risk over 9 years according to gender 
Table 3. Clinical and clinical-biological score parameters; all $p$ value - non significant

\begin{tabular}{llll}
\hline Variables & & Men & Women \\
\hline Clinical score & & & \\
Waist measurement & $70-79 \mathrm{~cm}$ & $3(5.7 \%)$ & $8(88.9 \%)$ \\
& $80-89 \mathrm{~cm}$ & $26(49.1 \%)$ & $0(0 \%)$ \\
& $90-99 \mathrm{~cm}$ & $17(32.0 \%)$ & $0(0 \%)$ \\
& $>99 \mathrm{~cm}$ & $7(13.2 \%)$ & $1(11.1 \%)$ \\
Smoker & & $17(32.1 \%)$ & $2(22.2 \%)$ \\
Family history of diabetes & & $7(13.2 \%)$ & $3(33.3 \%)$ \\
Blood pressure $\geq 140$ and/or $90 \mathrm{~mm} \mathrm{Hg}$ & $12(22.6 \%)$ & $0(0 \%)$ \\
Clinical-biological score & & & $1(11.1 \%)$ \\
Glycaemia & $5.6-5.9 \mathrm{mmol} / \mathrm{L}$ & $10(19.2 \%)$ & $2(22.2 \%)$ \\
& $\geq 6 \mathrm{mmol} / \mathrm{L}$ & $5(9.6 \%)$ & $1(11.1 \%)$ \\
Gamma glutamyl transferase & $20-44 \mathrm{UI} / \mathrm{L}$ & $30(55.5 \%)$ & $0(0 \%)$ \\
Triglyceridaemia & $\geq 45 \mathrm{UI} / \mathrm{L}$ & $8(14.8 \%)$ & $3(33.3 \%)$
\end{tabular}

Table 4. Classification of divers by gender and overall total with high diabetes risk scores

\begin{tabular}{lllll}
\hline \multirow{2}{*}{ Item } & & \multicolumn{2}{l}{ Number of divers presenting a high diabetes risk in 9 years } \\
\cline { 3 - 5 } & & Men & Women & Total \\
\hline Clinical score & $>3$ & $18(35.3 \%)$ & $2(22.2 \%)$ & $20(33.3 \%)$ \\
Clinical-biological score & Men $>7$ & $12(23.5 \%)$ & $3(33.3 \%)$ & $15(25.0 \%)$
\end{tabular}

The first stage of prevention is detecting cases at risk. Our study made it possible to show the feasibility of identifying and calculating risks for individuals using health care based on aptitude. The resulting preventative action focuses on two main areas: healthy lifestyle and diet and, in certain cases, use of pharmaceutical treatments. These lifestyle diet measures are: combatting obesity, balanced diet, stopping smoking, reducing alcohol consumption and physical activity [18]. All these measures are applicable in occupational health. Drug treatment measures, including metformin, should be discussed depending on the country $[19,20]$. However, certified hyperbaric doctors or occupation health doctors should be able to detect divers at risk of diabetes and inform them of this risk. Specialist advice from a doctor-nutritionist or endocrinologist could reduce the risk of developing diabetes and, consequently, increase divers' chances to stay in their careers.

\section{CONCLUSIONS}

It was possible to calculate the diabetes risk during medical follow-up of professional deep-sea divers. Amongst this population, $31.7 \%$ of the deep-sea divers had a predicted 9 -year risk of diabetes higher than $10 \%$. Prevention by giving advice on healthy lifestyle and diet seemed to be pertinent for this population, taking into consideration the increasing number of cases of this disease and the professional consequences of professional divers getting diabetes.

\section{REFERENCES}

1. Johnston WE, Viten-Johansen J, Santamore WP, Case LD, Little WC. Mechanism of reduced cardiac output during positive end -expiratory pressure in the dog. Am Rev Respir Dis 1989; 140: 1257-1264.

2. Frazier SK, Mozer DK, Stone KS. Heart rate variability and hemodynamic alterations in canine with normal cardiac function during exposure to pressure support, continuous positive airway pressure and a combination of pressure support and continuous airway pressure. Biol Res Nurs 2001; 2: 167-174.

3. Savitt MA, Rankin JS, Elberry JR, Owen $\mathrm{CH}$, Camporesi EM. Influence of hyperbaric oxygen on left ventricular contractility, total coronary blood flow, and myocardial oxygen consumption in the conscious dog. Undersea Hyperb Med 1994; 21: 169-183.

4. Regnard J, Le Péchon JC, Bouchard JL, Susbielle G, Philbert M. Analyse de la fréquence cardiaque de plongeurs saturés au travail. In: DeSola J, editor. EUBS 1984. Proceedings of the IXth Congress of the European Underwater Biomedical Society; 1984 September 23-25; Barcelone, Espagne. Barcelone: CRIS, 1984; pp. 369-376. In: Boussuges A, Regnard J. Physiologie Cardio-Vasculaire et Bilan Hydro-Minéral. Physiologie et médecine de la plongée pp. 115-139, Ellipses 2e édition, 2006, Paris. 
5. Pougnet R, Costanzo LD, Loddé B et al. Cardiovascular risk factors and cardiovascular risk assessment in professional divers. Int Marit Health 2012; 63: 164-169.

6. Lucas D, Loddé B, Choucroun P, Jegaden D, Mialon P, Sarni D, Dewitte J.D. Etude sur 5 ans de l'évolution de la fonction respiratoire d'une cohorte de 31 plongeurs professionnels. (A 5- year study on the changes in respiratory function of a group of 31 professional deep-sea divers). Med Marit 2005; 5: 17-28.

7. Cavenel PH. Aptitude à la plongée professionnelle. En Physiologie et médecine de la plongée (Aptitude for professional diving. In: Broussole B, Méliet JL, Coulange M eds. Physiology and medicine related to deep-sea diving. Ellpises, Paris, 2006; p. 577.

8. Vol S, Balkau B, Lange $C$ et al. Un score prédictif du diabète de type 2 en France: l'étude prospective Desir. (Predictive score of type 2 diabetes in France: Désir prospective study). BEH 2009; 9: 81-84.

9. Lindström J, Tuomilehto J. The diabetes risk score: a practical tool to predict type 2 diabetes risk. Diabetes Care 2003; 26: 725-731.

10. Makrilakis K, Liatis S, Grammatikou S, Perrea D, Stathi C, Tsiligros $\mathrm{P}$, Katsilambros $\mathrm{N}$. Validation of the Finnish diabetes risk score (FINDRISC) questionnaire for screening for undiagnosed type 2 diabetes, dysglycaemia and the metabolic syndrome in Greece. Diabetes Metab 2011; 37: 144-151.

11. Rosberger DF. Diabetic retinopathy: current concepts and emerging therapy. Endocrinol Metab Clin North Am 2013; 42: 721-745.
12. Charnogursky GA, Emanuele NV, Emanuele MA. Neurologic complications of diabetes. Curr Neurol Neurosci Rep 2014; 14: 457.

13. Dorresteijn JA, Kriegsman DM, Assendelft WJ, Valk GD. Patient education for preventing diabetic foot ulceration. Cochrane Database Syst Rev 2014; 12: CD001488.

14. Ferreira AC, Macedo FY. A review of simple, non-invasive means of assessing peripheral arterial disease and implications for medical management. Ann Med 2010; 42: 139-150.

15. Sehgal VN, Srivastava G, Aggarwal AK, Gupta M, Bhattacharya SN, Verma P. Noninsulin-dependent, type II diabetes mellitus-related dermatoses: part II. Skinmed 2011; 9: 302-308.

16. American Diabetes Association and National Institute of Diabetes, Digestive and Kidney Diseases. The prevention or delay of type 2 diabetes. Diabetes Care 2002; 25: 742-749.

17. American Diabetes Association. Prevention or delay of type 2 diabetes. Diabetes Care 2015; 38 (Suppl): S31-S32.

18. Diabetes Prevention Program Research Group. Reduction in the incidence of type 2 diabetes with lifestyle intervention or metformin. N Engl J Med, 2002; 346: 393-403.

19. Schwarz PE, Greaves CJ, Lindström J, Yates T, Davies MJ. Nonpharmacological interventions for the prevention of type 2 diabetes mellitus. Nat Rev Endocrinol 2012; 8: 363-373.

20. Walker KZ, O'Dea K, Gomez M, Girgis S, Colagiuri R. Diet and exercise in the prevention of diabetes. J Hum Nutr Diet 2010; 23: 344-352. 